\title{
The impact of COVID 19 crisis on revenue recognition for telecommunications sector
}

\author{
Valentin Ioan USURELU \\ Bucharest University of Economic Studies, Bucharest, Romania \\ valiusurelu@yahoo.com \\ Adriana DUTESCU \\ Bucharest University of Economic Studies, Bucharest, Romania \\ adriana.dutescu@bsm-mba.ro
}

\begin{abstract}
One of the most intricate and debated subject in international financial reporting convergence program was and remains the Revenue recognition. After a long due process, the new IFRS 15 standard was published in 2014 and mandatory implementing from 2018. From here, 2020 adds multiples difficulties due to COVID 19 pandemic effects. In this context, from the same starting point we continued our previous endeavor into current times. Despite the new financial reporting standard "smartness" and high-quality content, the entities' awareness and good understanding of the new standard's main issues are crucial for successful implementation. Likewise, the business-model's requirements and the way of caring them out are equally important. If in the precedent study we chose construction industry, now we extend the research to the telecommunications area - one of the most challenging sector - and we have considered the additional COVID 19 pandemic's sudden, unpredictable, and complex effects, using the same research methods (comparison analysis and the theoretical pattern), in order to produce a chain of evidence and to reduce biases. The main objective was to demonstrate a common pattern of challenges and controversies from these two hot-impact sectors' perspectives, alongside with the outcomes of the COVID 19 pandemic. We consider our effort to be helpful in finding the practical approach to improve the understanding and effective use of accounting information and to provide a value-added feedback to standard setters. Despite the inherent limitations of our research, we are confident that our findings originally contribute to increasing the knowledge of the relevant issues of financial reporting based upon IFRS and produce more "business light" to important global players.
\end{abstract}

Keywords: IFRS 15, Revenue Recognition, Accounting Convergence, Accounting harmonization, Accounting information quality.

\section{Introduction}

Global economic environment is changing faster than ever. As a response, International Accounting Standards Board (IASB) and Financial Accounting Standards Board (FASB) have issued the International Financial Reporting Standard (IFRS) 15 - Revenue from Contracts with Customers which seeks to address company business goals while also improving financial reporting quality and information transparency in a globally applicable and accepted method.

In summary, IFRS 15 is concerned with the recognition of various revenues, based upon the "five key steps" approach. This five steps model approach shall be consistently applied across businesses, industries and capital markets and it is designed to improve the comparability of financial statements to generate greater transparency and integrity of those statements.

The new accounting standard on revenue recognition, published by the IASB, is likely to have unprecedented impacts in the way revenue is recognized on telecommunications operators, the impact being stronger than for most of the other business sectors' entities, with a projected strong impact in these entities' financial information. Another challenge in revenue recognition for 
the telecommunications industry is bundled offerings. A significant change in the way in which bundled contracts are accounted for was introduced by the RevRec project, which later became IFRS 15.

The new standard replaced the legacy IAS 18 (International Accounting Standard 18 Revenue) which had first been issued in 1981 as well as IAS 11 (International Accounting Standard 11 Construction Contracts) which had first been issued in 1979. The last significant revision to each of these standards was in 1993.

Considering the complexity of the approaches resulting from the new standard, a short comparative analysis is performed on the content or in relation to the other standards, as it follows:

\section{Table 1. Size of IFRS 15}

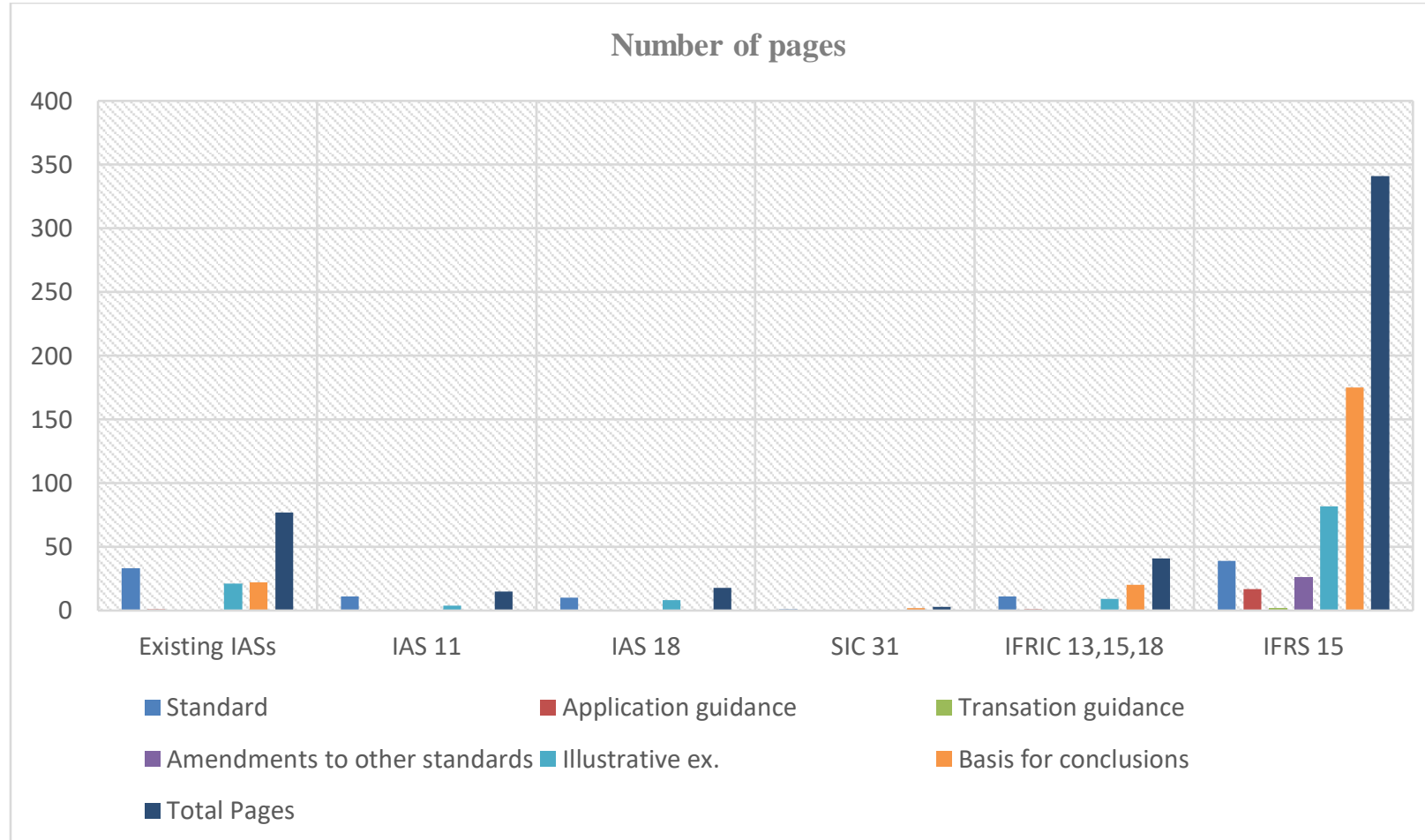

Source: Authors' own contribution.

A more detailed standard the "fresh" IFRS 15, is coming with some of the most significant milestones:

- In IFRS 15, where performance obligations are a key concept of analysis, the separation between different components in one contract is more detailed.

- Warranties are also handled differently, as an abnormal warranty may result in revenue being excluded under IAS 18, based on the argument that not all significant risks were transferred to the customer, which is not possible under IFRS 15 - and in some cases, it may even accelerate revenue recognition.

- As previously stated, more specific and thorough instructions, specifically in the allocation of discounts between contract components, increased the importance of variable consideration.

- While revenue recognition was primarily based on a risk-and-reward strategy under IAS 18, IFRS 15 moves away from this view and it is now much more common, in some industries, to 
recognize revenue over time (even in cases of goods sold), as revenue recognition more based on a control transfer approach.

- The capitalization of costs has suffered many developments in this new standard, as the concept of an asset originated from the capitalization of incremental costs to obtain a contract did not exist in previous standards (Ferreira, 2020).

The following table is summarizing the main differences between the two frameworks on revenue recognition:

"Big-4""s studies carried out to assess or forecast the impact that IFRS 15 has in various sectors, have unanimous concluded that the telecommunications industry would record greater impacts than other industries (Mattei \& Paoloni, 2018), as it is summarized in Table 3 below:

Table 2. Forecast of the impact of IFRS 15 by sectors

\begin{tabular}{|l|l|l|l|l|}
\hline \multicolumn{1}{|c|}{ PWC } & \multicolumn{1}{c|}{ KPMG } & \multicolumn{1}{c|}{ EY } & SECTOR & \multicolumn{1}{c|}{ SECTOR } \\
\hline N/a & Medium & Medium/low & N/a & Insurance \\
\hline High & High & High & High & Telecommunication \\
\hline Medium & Medium/High & Medium & Medium & Building and construction \\
\hline Medium & Medium & Medium & Medium & Retail and consumer goods \\
\hline Medium & $\begin{array}{l}\text { Medium/ } \\
\text { High }\end{array}$ & N/a & Medium & Licensors (life science, franchisors, media) \\
\hline Medium & Medium & N/a & Medium & Real estate \\
\hline High & Medium & N/a & $\begin{array}{l}\text { Medium/ } \\
\text { low }\end{array}$ & Rechnology \\
\hline Low & Medium & Medium & Medium & Energy (oil, mining and gas) \\
\hline Low & Medium & N/a & N/a & Transport \\
\hline
\end{tabular}

Source: Authors' contribution.

In Romania, only listed companies are required, in accordance with the Order of the Ministry of Public Finance 2844/2016, the Order of the Ministry of Public Finance 881/2012 and the Order of the National Bank of Romania 8/2019, to adopt IFRSs for individual annual financial statements (Usurelu \& Dutescu, 2020).

Following the worldwide movement towards the implementation of IFRS 15, Romanian telecom industry should be encouraged to voluntarily adopt the provisions of the new standard, to create uniform practices and integrated global accounting.

The goal of our analysis is to define the implications of IFRS 15 for the telecommunication industry and some sensitive issues related to its adoption, including the area of critical judgement.

\section{Literature review}

The first impact of IFRS 15 is due to its main topic: revenue is considered an important measure of an entity's performance, because it is used by both investors and other stakeholders, so that investment decisions can be made (Tong, 2014). In essence, one of the most important aspects of financial reporting is revenue. (Aladwan, 2019), because it can be easily examined and is one of the most important sources of earnings that is susceptible to discretion (Stubben, 2010).

The importance of this new standard is was clearly stated by Russel Golden, Chairman of the FASB "The revenue recognition standard represents a milestone in our efforts to improve and 
converge one of the most important areas of financial reporting." However, the author also admits that there is still a long way to go, but the emerge of this standard is an important step into the financial information increasing reliability (Ferreira, 2020).

Board members of the IASB believe "that the approach to revenue recognition that we have developed will provide a more consistent basis for reporting revenue and produce accounting that more closely matches the underlying economics of transactions" (Cooper, 2010).

Nevertheless, the devil is in details. Weaknesses and inconsistencies in the existing revenue guidance often led to different accounting effects for economically similar transactions. With revenue as the "top line" matrix and its importance in supporting material decisions, the issuance of IFRS 15 is a significant milestone in financial reporting (Usurelu \& Dutescu, 2020).

The core event of the new revenue standard shifts from the transfer of risks and rewards to the consumer to the transfer of control of the same goods or service (Fonseca and Azevedo, 2020). As a result, because it is mainly responsible for a change in revenue recognition's timing, the longterm effects are less evident than the short-term ones, which can impact also dividend policy, creditworthiness, and current tax obligations (Brozovic \& Pavic, 2018).

There is also some evidence that there is a significant difference between the value of the revenue before and after the implementation of the new standard in terms of incomes (Chayomchai, 2020). From here it appears that the market captures the changes, and the impact will be reflected on stock prices (Aladwan, 2019).

Peters presented the challenges of the transition to IFRS 15 as an opportunity for the investors to understand the underlying business, the quality of the earnings and the relationship of the company with its customers. More than that, Peters suggested that investors should formulate some expectations regarding the new financial information generated by the standard implementation and if these expectations are not met or properly disclosed in the financial statements, to require clarifications from company's executives (Peters, 2018) (Usurelu \& Dutescu, 2020).

Considering the amount of revenue and contract costs, IFRS 15 could have a significant impact. The timing of their recognition may differ significantly from the current practice, that some additional disclosures are required by this standard (Mattei \& Paoloni, 2018).

The degree of professional judgment now involved in revenue recognition, as the principlebase model will require accountants to use additional professional judgment in measuring companies' performance obligations and the timing of their satisfaction, was one of the topics that generated more discussion following the issuance of IFRS 15 (Jones \& Pagach, 2013).

Many research are attempting to answer the question of how the new standard impacted earnings quality, which also highlights the importance of information in decision-making (Statement of Financial Accounting Concepts No. 1 (SFAC No. 1)). Earnings quality, on the other hand, is an abstract concept that is difficult to measure (Rutledge, Karim, \& Kim, 2016). For example, (Dechow, Ge, \& Schrand, 2010) referred to various earnings quality proxies, as measures of accounting information's quality, such as earnings persistence, accrual qualities, volatilities and relevance of earnings and earnings restatements (Ferreira, 2020). The comparability of information between industries, which reduces the difficulty of identifying opportunistic behavior (Tutino, Regoliosi, Mattei, Paoloni, \& Pompili) as well as the higher level of disclosures, which reduces the possibility of leading opportunistic behavior (Leuz \& Verrecchia, The economic consequences of increased disclosure., 2020), (Ashbaugh \& Pincus, 2001) and (Leuz, 2003) are among the most common arguments in favor of increasing the quality of the IFRS. 
If IFRS 15 has an influence on earnings quality, it is widely accepted that the impact grows as the level of judgment increases. Furthermore, the available statistical research revealed that earnings management practices are "frequently applied" in the telecommunications business, which is one of the industries most affected by the implementation of IFRS 15 . This fact raises questions about the monitoring process of the new principle, written to discipline the accountancy of revenues, and its consequences (Tutino, Regoliosi, Mattei, Paoloni, \& Pompili).

\section{Methodology}

This paper is a continuation of the previous scientific study, where we consolidated the existing pattern of challenges and controversies in the construction sector. Due to the encouraging conclusions we decided to expand our research on another significant area, the telecommunications industry, also referring to the impact of the global health crisis on revenue recognition.

The coronavirus pandemic has been dominating the global economy since the spring of 2020. While the measures adopted to curb the pandemic have catapulted the global economy into the worst slump since the end of the Second World War, according to leading economic forecasting institutes the worst is now behind us. The International Monetary Fund (IMF) announced in the October 2020 update to its forecast that it expects the global economy to contract by 4.4 percent in 2020 , followed by expansion of 5.2 percent in 2021. The global economy was likely to rebound partially in 2021 but remained well below the estimated level prior to the outbreak of the coronavirus crisis.

The main objective of this article is to analyze the general impacts and implications resulting from the application of IFRS 15 for telecommunications companies. The second goal is to analyze the real consequences resulting from the application of IFRS 15 during the coronavirus pandemic (at the level of the revenue assembly line - the 5 steps revenue recognition model). The third objective is to extrapolate the real consequences found at the contract level to the accounting (the way companies recognize, measure, present and disclose their revenues) and cognitive (the way companies and their transactions are understood, both internally and externally) consequences at the organization level by empirical analysis of the main indicators reported by the selected companies. Our evidence is mainly based on corporate 2020 and 2019's nine months financial statements.

The theoretical approach was based on the ontological and epistemological capture of the researched subject. So, through the dichotomy of the cognitive-real paradigm perspective we used a modified version of the Napier\&Stadler's accounting effects concept (Napier \& Stadler, 2020) as a main matrix of research to structure our study.

In Figure 1 we represented the correlations between the types of consequences. The blue arrow represents direct accounting effects. The solid single arrows represent primary additional effects. The dashed single arrows represent secondary additional effects. The dashed single arrows going into accounting consequences represent indirect accounting effects. 


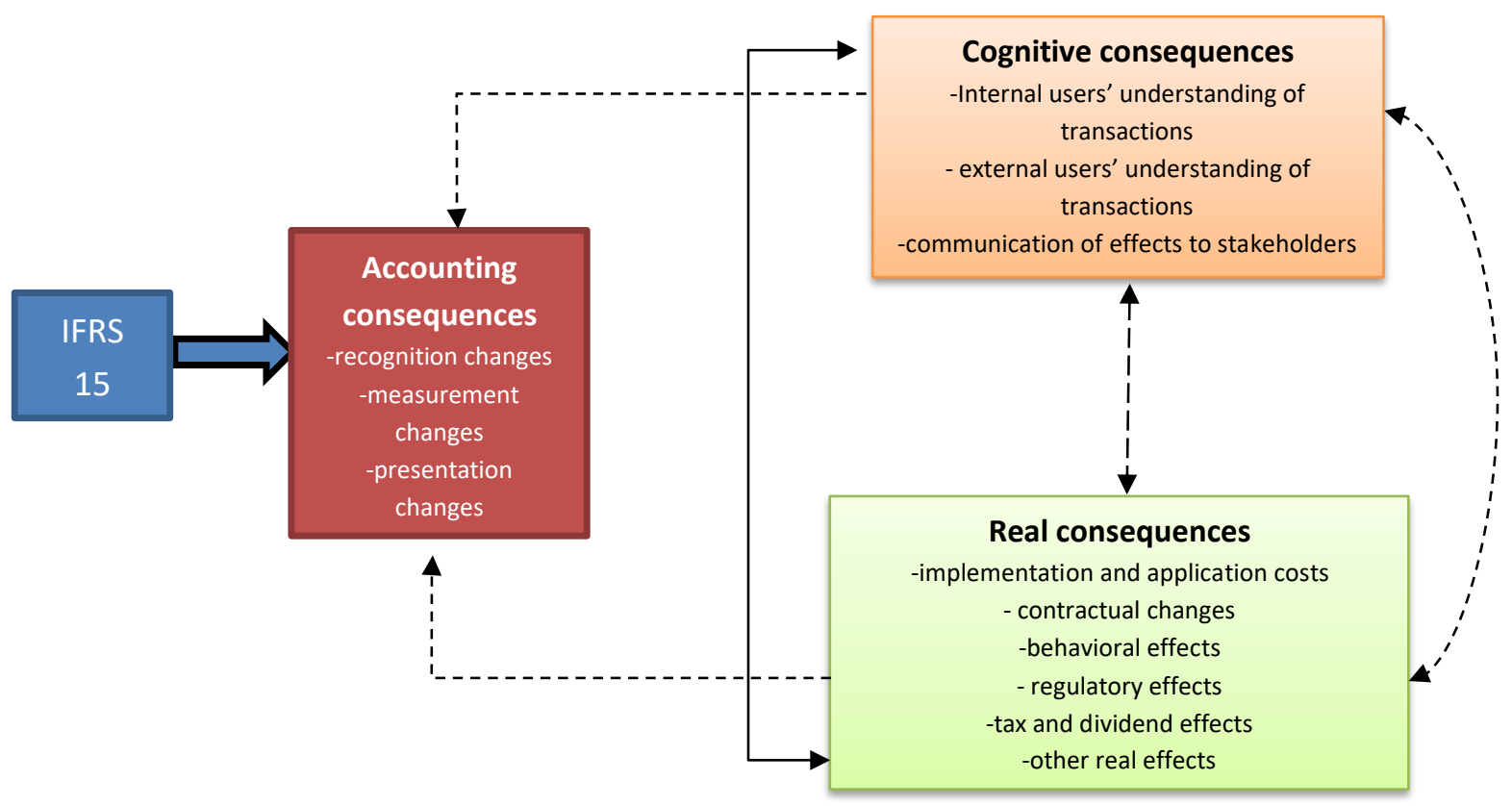

PICBE | 798

Figure 1. Consequences of a new accounting standard

Source: Insipred from Napier\&Stadler (2020).

We adopted a standardized approach to identification, conducting the following search: in each financial statement at 9 months of 2020 of each company, we searched for the keywords "IFRS 15" and "COVID-19". The results were described below for each company.

In order to achieve the empirical evidence, we considered to choose in this research the entities that make up the top 10 telecommunications corporate groups in continental Europe, namely Orange France, Telekom Germany, Alice International Portugal, Telefonica Spain and Telecom Italy. We had in mind that in the selection of these companies we can highlight a pattern at European level, as a result we aimed to ensure that the 5 chosen belong to the most developed countries at European level.

Starting from the opinions and studies carried out by researchers in this area, the previsions IFRS's requirements, from the difficulties encountered by telecom entities in the process of implementing (practical examples) and the resulting economic aspects, we have decided to use the content analysis method to determine the broad impact of the application of these guidelines by answering the research questions below:

1. How should revenue be allocated to different goods and services identified (e.g. mobile phone handsets)?

2. Do the customer's options (material rights) require careful analysis?

3. What is the impact if a contract is modified? Should contract costs be capitalised (e.g. sales commissions and success fees)?

4. From an accounting point of view, do the elements that could lead to obtaining or fulfilling a contract change?

5. It is necessary to revise for tax planning, covenant compliance and for sales incentives schemes?

6. Should sales and contracting processes be reconsidered? 
7. Will there be a need for greater pressure to the review of accounting processes and internal controls? Could the requirements of the new standard have implications for IT systems?

8. Should contract costs be capitalised (e.g. sales commissions and success fees)?

9. Will there be a need for further extensive disclosures? Will telecoms companies have to issue new estimates and judgments?

10. Should revenue be adjusted for the effects of the time value of money?

\section{Results and discussions}

The new standard provides a framework (Deloitte, 2014) that replaces existing revenue guidance in US GAAP and IFRS, including the contingent cap. It moves away from the industry-and transaction-specific requirements under US GAAP, which are also used by some IFRS preparers in the absence of specific IFRS guidance.

The new standard envisaged by the IASB and the FASB had several disadvantages for communications companies. The main one is that the application of the new standard would be complex and costly due to the high volume of contracts and their disparities. So a significant change in information systems was becoming more than necessary. Furthermore, a significant management judgement is needed when required an estimation of standalone selling prices of the handset and network service which could lead to reduced comparability of financial reporting between companies.

Therefore, bundled telephones with service contracts by most telecommunications operators involve the allocation of higher revenues than previous IAS 18. New qualitative and quantitative disclosure requirements aim to enable financial statement users to understand the nature, amount, timing and uncertainty of revenue and cash flows arising from contracts with customers.

Investors should take the time to understand the new regulations introduced by IFRS 15 , find concrete ways to apply them, and be able to track and analyze the information provided by companies.

Our main sources of inspiration used in the content analysis were financial audit reports and supplements on the impact of IFRS 15 on the telecommunications sector of the largest companies in the market (KPMG, Deloitte and PWC).

Question 1: How should revenue be allocated to different goods and services identified (e.g. mobile phone handsets)?

Previously, with the lack of detailed instructions in IFRSs, when determining the goods and services under a contract and then allocating the revenue to those goods and services, there was more room for judgment. As a consequence of more detailed guidelines in IFRS 15, companies may have to change their existing accounting practices.

Within the telecommunications industry it is common for handsets to be subsidised by the providers of airtime and to be viewed as a cost of doing business (Deloitte, IFRS industry insights. Telecommunications sector, 2014). Previously, any revenue allocated to the handset has often been limited to the amount, if any, explicitly paid by the customer towards the handset.

For certain organizations, this will substantially change the profile of revenue identification because, due to the sheer number of consumers with different tariffs and service arrangements, entities will have to resolve substantial logistical challenges to ensure their processes are in order to meet the current criteria.

In comparison with previous disclosure practice, revenue recognition for handsets can be accelerated. This is attributed to the fact that the new standard excludes the contingent cap 
approach, used by certain telecommunications companies when accounting for wireless sales. The new standard replaces the contingent cap approach with a provision that telecom organizations determine the volume of revenue for each element in a package by allocating the sale price based on stand-alone selling prices (KPMG, 2016).

Question 2: Do the customer's options (material rights) require careful analysis?

The new standard requires a telecommunications entity to assign a transaction price to options for the purchase of additional goods and services which offer a material right to a customer. This would take close consideration, given the breadth of offers provided by telecom entities, which could potentially result in revenue deferral until such options are exercised or expire. (Deloitte, IFRS industry insights. Telecommunications sector, 2014)

Question 3: What is the impact if a contract is modified? Should contract costs be capitalised (e.g. sales commissions and success fees)?

In the telecommunications industry, it is very popular to allow the client to change their contracts, for instance, increase or decrease minutes or add or eliminate services. This may lead to a change of procedure for certain companies and, again, as a result of the large number of different permutations of products and services under contracts, may pose a logistical challenge for the industry. It will be necessary to determine whether, by operating with current accounting systems, it is feasible to deal with such modifications or whether improvements to those systems will be needed.

The new standard provides, in addition to more prescriptive guidelines on revenue recognition, specific requirements to decide whether to capitalize on certain costs, distinguishing between the costs associated with the purchase of a contract (e.g. sales commissions) and the costs associated with fulfilling a contract. This becomes a concern in the telecommunications industry as there are substantial incurred costs that are directly due to obtaining contracts with consumers, such as 'success fees' e.g. commissions that are only payable if a contract is obtained. Currently, various organizations can treat these costs differently, while they have been previously expensed by most. IFRS 15 would include the capitalization of success fees by companies, which will have an effect on operating results. Moreover, the current standard includes the amortization of the capitalized contract costs on a systematic basis, consistent with the pattern of movement of goods or services (KPMG, 2016) (PWC, 2017).

Question 4: From an accounting point of view, do the elements that could lead to obtaining or fulfilling a contract change?

Incremental costs for the acquisition of a contract and some costs for fulfilling a contract are capitalized and amortized over the duration of delivery of goods and services under the new standard. This could reflect a shift in accounting strategy for certain telecommunication s companies that are currently expensing certain costs. We assume some of the diversity in current practice may be reduced by the new standard (KPMG, 2016).

Question 5: It is necessary to revise for tax planning, covenant compliance and for sales incentives schemes?

In certain countries, the timing of tax payments, the ability to pay dividends and compliance with the covenant can all be affected. Revised tax planning could be needed for tax changes caused by modifications to the timing and amounts of income, expenditures and capitalized costs. In order to ensure that they stay consistent with organizational priorities, telecoms entities would need to review workers bonuses and incentive plans (Deloitte, 2014).

Question 6: Should sales and contracting processes be reconsidered? 
To achieve or maintain a certain revenue profile, some companies may wish to rethink existing contract terms and business practices, such as distribution channels.

Question 7: Will there be a need for greater pressure to the review of accounting processes and internal controls? Could the requirements of the new standard have implications for IT systems?

Telecom companies also need mechanisms to collect new information at their source, such as customer service procedures, operations, marketing deals and new product launches, and to better record the new processes and information, particularly as they relate to forecasts and decisions. Companies would also need to ensure that controls are in place, relying on standardized methodologies for both transaction price adjustment and contract modification accounting. To ensure the completeness and precision of all this information, new internal controls would be needed. Entities would still need to gather the extra information required by the current standard, such as data used to estimate independent selling prices and help disclosures (Deloitte, 2014) and (KPMG, 2016).

Question 8: Should contract costs be capitalised (e.g. sales commissions and success fees)?

The new standard provides, in addition to more prescriptive guidelines on revenue recognition, specific requirements to determine whether to capitalize on certain costs, distinguishing between the costs associated with the acquisition of a contract (e.g. sales commissions) and the costs associated with fulfilling a contract. This is a challenge in the telecommunications sector since significant costs are incurred that are directly attributable to obtaining contracts with consumers, such as performance fees - commissions that are only payable if a contract is obtained.

These costs will currently be handled differently by various entities, as most of them have previously been expended. The new standard would include the capitalization of success fees by companies, which will have an effect on operating results. Moreover, the new standard includes the amortization of the capitalized contract costs on a gradual basis, consistent with the pattern of transfer of goods or services. In order to determine the appropriate basis and time period for this amortization, the entities will have to exercise all the necessary diligence (KPMG, 2016) and (PWC, 2017).

Question 9: Will there be a need for further extensive disclosures? Will telecoms companies have to issue new estimates and judgments?

It can be time consuming to prepare new disclosures, and it can require incremental effort or system changes to capture the required details. For commercially sensitive information, there are no exemptions. In order to report the effect of recently issued accounting standards on financial statements as implemented, telecommunications companies may also need to recognize IFRS, SEC and other regulatory criteria. The new standard incorporates new projections and judgmental thresholds that will impact the recognized revenue amount or timing. Judgments and forecasts would need to be revised, potentially leading to further revisions to the financial statements in future periods for changes in estimates (KPMG, 2016) and (PWC, 2017).

Question 10: Should revenue be adjusted for the effects of the time value of money?

The new standard offers new and broader guidance on financing arrangements and the effect of money time value. Under IFRS 15, the financing component is accounted for separately from revenue if it is relevant. This applies to payments made both in advance and in arrears but is subject to an exception when there is less than one year between payment and transfer of goods or services. In some circumstances, this new guidance can change current accounting practices. For example, the time value of money would have to be weighed by telecommunications providers who 
sell discounted hardware (e.g. handsets, modems or set-top boxes) to clients whose contracts are paid over a period of more than 12 months (PWC, 2017).

After pointing out in the content analysis through the answers to the research questions the general impact and the particularities brought by the requirements of the new standard, in the following we will track the impact of the COVID-19 crisis on the revenue assembly line (five-step process for revenue recognition) for the telecommunications companies. The health crisis has the potential to have an impact on both existing and future customer contracts.

Table 3. Contractual elements to be analyzed at the entity level

\begin{tabular}{|c|c|c|c|}
\hline & $\begin{array}{c}\text { Impact } \\
\text { on the contract }\end{array}$ & $\begin{array}{c}\text { The predicted COVID-19 real } \\
\text { consequences }\end{array}$ & $\begin{array}{l}\text { Accounting considerations } \\
\text { on revenue assembly line }\end{array}$ \\
\hline 1 & $\begin{array}{l}\text { Contract modifications } \\
\text { and terminations }\end{array}$ & $\begin{array}{l}\text { The global context, the current } \\
\text { economic conditions as well as the } \\
\text { uncertainties related to the COVID- } 19 \\
\text { pandemic may determine the } \\
\text { modification of certain provisions of } \\
\text { their contracts with customers by } \\
\text { telecommunications companies. The } \\
\text { termination of all or part of their } \\
\text { contracts before the end of the } \\
\text { contract may also be considered. }\end{array}$ & $\begin{array}{l}\text { Step } 1 \\
\text { - changes to the contract term is a form } \\
\text { of contract modification which occurs } \\
\text { when the parties to a contract agree to } \\
\text { change the scope or price or both and the } \\
\text { changes either create new enforceable } \\
\text { rights and obligations of the parties or } \\
\text { change their existing rights and } \\
\text { obligations; } \\
\text { - accounting for a contract modification } \\
\text { as either a separate, standalone contracts; } \\
\text { - or combined with the original contract } \\
\text { and accounted for as one contract which } \\
\text { is then accounted for either prospectively } \\
\text { or on a cumulative catch-up basis. }\end{array}$ \\
\hline 2 & $\begin{array}{l}\text { Collectibility and } \\
\text { extended payment terms }\end{array}$ & $\begin{array}{l}\text { If entities want to sell } \\
\text { products/services to their customers, } \\
\text { especially those significantly affected } \\
\text { by COVID-19, then they will need to } \\
\text { assess each customer's ability to make } \\
\text { payments and whether adjustments to } \\
\text { existing receivables are necessary. } \\
\text { New judgments are needed to continue } \\
\text { to recognize revenue for future } \\
\text { customer transactions in similar } \\
\text { situations. }\end{array}$ & $\begin{array}{l}\text { Step } 1 \\
\text { - for a contract to exist, it must be } \\
\text { concluded that an entity is likely to } \\
\text { collect substantially all the consideration } \\
\text { to which it will be entitled under the } \\
\text { agreement. }\end{array}$ \\
\hline 3 & Material right & $\begin{array}{l}\text { The marketing strategy of each } \\
\text { company is to mitigate a drastic drop } \\
\text { in sales; therefore, entities can extend } \\
\text { incentives to their customers, } \\
\text { discounts on future goods or services, } \\
\text { including those offered in a period of } \\
\text { renewal. }\end{array}$ & $\begin{array}{l}\text { Step } 2 \\
\text { - entities are required to assess whether } \\
\text { sales incentives for the purchase of } \\
\text { future goods or services indicate } \\
\text { whether the customer has a significant } \\
\text { right that should be accounted for as a } \\
\text { separate performance obligation } \\
\text { (material right); } \\
\text { - or represents a discount that is } \\
\text { recognized in the future when revenue } \\
\text { is recognized for the related goods or } \\
\text { services. }\end{array}$ \\
\hline
\end{tabular}




\begin{tabular}{|c|c|c|c|}
\hline & $\begin{array}{c}\text { Impact } \\
\text { on the contract }\end{array}$ & $\begin{array}{c}\text { The predicted COVID-19 real } \\
\text { consequences }\end{array}$ & $\begin{array}{l}\text { Accounting considerations } \\
\text { on revenue assembly line }\end{array}$ \\
\hline 4 & $\begin{array}{l}\text { Significant financing } \\
\text { components }\end{array}$ & $\begin{array}{l}\text { Companies will develop strategies to } \\
\text { help customers facing financial } \\
\text { difficulties. Thus, when purchasing } \\
\text { goods and services, customers can } \\
\text { benefit from extended payment terms } \\
\text { and those with liquidity problems can } \\
\text { make advance payments. }\end{array}$ & $\begin{array}{l}\text { Step } 3 \\
\text { - entities should assess whether there is } \\
\text { a significant funding component. If } \\
\text { entities change the payment terms for an } \\
\text { existing contract with customers, they } \\
\text { should evaluate this type of change } \\
\text { similar to the price concessions } \\
\text { discussed in the variable consideration } \\
\text { below. }\end{array}$ \\
\hline 5 & Variable consideration & $\begin{array}{l}\text { Types of estimates that may be } \\
\text { affected by the pandemic include: } \\
\text {-price concessions, incentives or other } \\
\text { adjustments to the transaction price to } \\
\text { help customers whose businesses are } \\
\text { affected by COVID-19. } \\
\text {-expected returns, reductions, } \\
\text { reimbursements of goods and } \\
\text { expectations of both contractual } \\
\text { volumes and whether an entity will } \\
\text { meet the contractual conditions for } \\
\text { performance bonuses or penalties. }\end{array}$ & $\begin{array}{l}\text { Step } 3 \\
\text { - the transaction price may have fixed } \\
\text { and/or variable consideration } \\
\text { components. } \\
\text { - variable consideration prezume a } \\
\text { three-step approach to consider: } \\
\text { a) estimate the variable consideration at } \\
\text { contract inception } \\
\text { b) apply a constraint to that estimate; } \\
\text { c) reassess this estimate and any } \\
\text { constraints at each reporting date } \\
\text { considering current circumstances. } \\
\text { Constraining variable consideration } \\
\text { means that the estimated transaction } \\
\text { price only includes the amount of } \\
\text { consideration where it is probable that } \\
\text { there will not be a subsequent } \\
\text { significant reversal in the amount of } \\
\text { revenue recognized at the point at which } \\
\text { uncertainty over the amount of variable } \\
\text { consideration is resolved. }\end{array}$ \\
\hline
\end{tabular}

DOI: 10.2478/picbe-2021-0074, pp. 793-810, ISSN 2558-9652 |

Proceedings of the $15^{\text {th }}$ International Conference on Business Excellence 2021 


\begin{tabular}{|c|c|c|c|}
\hline & $\begin{array}{c}\text { Impact } \\
\text { on the contract }\end{array}$ & $\begin{array}{c}\text { The predicted COVID-19 real } \\
\text { consequences }\end{array}$ & $\begin{array}{l}\text { Accounting considerations } \\
\text { on revenue assembly line }\end{array}$ \\
\hline 6 & Recognition of revenue & $\begin{array}{l}\text { The potential disruption of supply in } \\
\text { the context of the COVID-19 crisis } \\
\text { and other unfavorable circumstances } \\
\text { may put an entity in a position to } \\
\text { reconsider the timing of revenue } \\
\text { recognition if it is unable to meet its } \\
\text { performance obligations in a timely } \\
\text { manner. For example, when entities } \\
\text { are unable to meet their stand-ready or } \\
\text { similar obligations due to downtime. }\end{array}$ & $\begin{array}{l}\text { Step } 5 \\
\text { - revenue recognition should not take } \\
\text { place until the control of the goods or } \\
\text { services is transferred to the customer } \\
\text {-in circumstances where an entity is } \\
\text { unable to meet its performance } \\
\text { obligations in a timely manner, there } \\
\text { may be a delay in recognizing revenue } \\
\text { until the entity is able to perform under } \\
\text { the contract. } \\
\text {-if the arrangements result in contractual } \\
\text { penalties for non-performance or delay } \\
\text { in performance, entities should assess } \\
\text { how this may affect the transaction price } \\
\text { in accordance with Step } 3 \text {. } \\
\text { - in situations where entities are } \\
\text { completely unable to satisfy their } \\
\text { performance obligation(s), the } \\
\text { appropriate accounting impact needs to } \\
\text { be considered which could result in } \\
\text { either the termination of the contract, } \\
\text { reversal of any revenue previously } \\
\text { recognized for a performance obligation } \\
\text { that was not fully satisfied, or the } \\
\text { recognition of a refund liability (or } \\
\text { additional liability due to a payment of } \\
\text { penalties) instead of deferred revenue. }\end{array}$ \\
\hline 7 & Capitalized contract costs & $\begin{array}{l}\text { The current economic context leads to } \\
\text { impairment costs for contractual } \\
\text { assets when the carrying amount } \\
\text { exceeds the recoverable amount. }\end{array}$ & $\begin{array}{l}\text { According to IFRS 15- Capitalizable } \\
\text { costs may include the following: } \\
\text {-completion costs e.g., direct labor, } \\
\text { materials, other costs that may be borne } \\
\text { by a client's contract) that are not } \\
\text { subject to other accounting rules (these } \\
\text { types of costs are capitalized if they } \\
\text { relate directly to a contract, generate or } \\
\text { increase the entity's resources used to } \\
\text { fulfill a performance obligation and are } \\
\text { expected to be recovered in future } \\
\text { periods). } \\
\text {-contract acquisition costs that are } \\
\text { capitalized and amortized over the } \\
\text { period in which the goods or services } \\
\text { are transferred to the customer. }\end{array}$ \\
\hline
\end{tabular}

Source: Authors' contribution

Finally, we empirically researched the predicted consequences of major changes in the way companies recognize, measure, present and disclose revenue, analyzing as proxies for real consequences the most relevant indicators (revenue, EBIT AL, net profit, cash-flow, equity) and for cognitive consequences the level of disclosure ( $\mathrm{kb}$ dimension of the financial statements files on the reporting entity's official website).

DOI: 10.2478/picbe-2021-0074, pp. 793-810, ISSN 2558-9652 |

Proceedings of the $15^{\text {th }}$ International Conference on Business Excellence 2021 
We have chosen five of the leading communications companies, Orange (France), Deutsche Telekom (Germany), Altice INTL. (Portugal), Telefonica (Spain), and TIM (Italy).

The data used in this study have been extracted from the 2020 and 2019 nine months financial statements of each company, from their official website. It should be mentioned that some financial information related to the indicators we assessed could not be identified for Orange (France).

Table 4. Key financial and accounting numbers for corporate group

\begin{tabular}{|c|c|c|c|c|c|c|c|c|c|c|}
\hline \multicolumn{11}{|c|}{ KEY FINANCIAL AND ACCOUNTING NUMBERS FOR CORPORATE GROUP } \\
\hline & & $\begin{array}{l}\text { ORANGE } \\
\text { FRANCE }\end{array}$ & $\begin{array}{l}\text { TELEKOM } \\
\text { GERMANY }\end{array}$ & $\begin{array}{l}\text { ALTICE } \\
\text { INTI. }\end{array}$ & $\begin{array}{c}\text { TELEFONICA } \\
\text { SPAIN }\end{array}$ & $\begin{array}{l}\text { Telecom } \\
\text { ITALY }\end{array}$ & Mean & Median & Min & Max \\
\hline \multirow[t]{3}{*}{$\begin{array}{l}\text { Revenue } \\
\text { (MEUR) }\end{array}$} & 9m 2019 & $31.150,00$ & $59.169,00$ & $2.997,40$ & $36.023,00$ & $13.423,00$ & & & & \\
\hline & $9 \mathrm{~m} 2020$ & $31.353,00$ & $73.377,00$ & $2.956,40$ & $32.167,00$ & $11.657,00$ & & & & \\
\hline & $\Delta \mathrm{R}(\%)$ & $0,65 \%$ & $24,01 \%$ & $-1,37 \%$ & $-10,70 \%$ & $-13,16 \%$ & $-0,11 \%$ & $5,43 \%$ & $-13,16 \%$ & $24,01 \%$ \\
\hline \multirow[t]{3}{*}{$\begin{array}{l}\text { EBITA } \\
\text { AL } \\
\text { (MEUR) }\end{array}$} & 9m 2019 & $9.570,00$ & $18.701,00$ & $1.153,40$ & $11.450,00$ & $5.068,00$ & & & & \\
\hline & $9 \mathrm{~m} 2020$ & $9.498,00$ & $26.065,00$ & $1.149,30$ & $9.747,00$ & $4.678,00$ & & & & \\
\hline & $\Delta \mathrm{EB}(\%)$ & $-0,75 \%$ & $39,38 \%$ & $-0,36 \%$ & $-14,87 \%$ & $-7,70 \%$ & $3,14 \%$ & $12,25 \%$ & $-14,87 \%$ & $39,38 \%$ \\
\hline \multirow[t]{3}{*}{$\begin{array}{l}\text { Margin } \\
(\%) \\
\text { (MEUR) }\end{array}$} & 9m 2019 & $30,72 \%$ & $31,61 \%$ & $38,48 \%$ & $31,79 \%$ & $37,76 \%$ & & & & \\
\hline & $9 \mathrm{~m} 2020$ & $30,29 \%$ & $35,52 \%$ & $38,87 \%$ & $30,30 \%$ & $40,13 \%$ & & & & \\
\hline & $\begin{array}{l}\triangle \mathrm{MGPR} \\
(\%)\end{array}$ & $-1,39 \%$ & $12,39 \%$ & $1,03 \%$ & $-4,67 \%$ & $6,29 \%$ & $2,73 \%$ & $3,86 \%$ & $-4,67 \%$ & $12,39 \%$ \\
\hline \multirow[t]{3}{*}{$\begin{array}{l}\text { Net profit } \\
\text { (loss) } \\
\text { (MEUR) }\end{array}$} & 9m 2019 & N/A & $3.213,00$ & $-125,40$ & $1.787,00$ & 852,00 & & & & \\
\hline & $9 \mathrm{~m} 2020$ & N/A & $2.487,00$ & 352,80 & 866,00 & $1.178,00$ & & & & \\
\hline & $\Delta \mathrm{NP}(\%)$ & N/A & $-22,60 \%$ & $381,34 \%$ & $-51,54 \%$ & $38,26 \%$ & $86,37 \%$ & $164,90 \%$ & $-51,54 \%$ & $381,34 \%$ \\
\hline \multirow[t]{3}{*}{$\begin{array}{l}\text { Margin } \\
(\%) \\
(\text { MEUR) }\end{array}$} & 9m 2019 & N/A & $5,43 \%$ & $-4,18 \%$ & $4,96 \%$ & $6,35 \%$ & & & & \\
\hline & $9 \mathrm{~m} 2020$ & N/A & $3,39 \%$ & $11,93 \%$ & $2,69 \%$ & $10,11 \%$ & & & & \\
\hline & $\begin{array}{l}\begin{array}{l}\Delta \mathrm{MNPR} \\
(\%)\end{array}\end{array}$ & N/A & $-37,58 \%$ & $-385,24 \%$ & $-45,73 \%$ & $59,21 \%$ & $-102,34 \%$ & $-163,02 \%$ & $-385,24 \%$ & $59,21 \%$ \\
\hline \multirow{3}{*}{$\begin{array}{l}\text { Cash flow } \\
\text { (MEUR) }\end{array}$} & $9 \mathrm{~m} 2019$ & $4.336,00$ & $10.043,00$ & 442,40 & $8.778,00$ & $2.791,00$ & & & & \\
\hline & $9 \mathrm{~m} 2020$ & $4.613,00$ & $11.512,00$ & 266,60 & $5.913,00$ & $2.374,00$ & & & & \\
\hline & $\Delta \mathrm{CF}(\%)$ & $6,39 \%$ & $14,63 \%$ & $-39,74 \%$ & $-32,64 \%$ & $-14,94 \%$ & $-13,26 \%$ & $-12,56 \%$ & $-39,74 \%$ & $14,63 \%$ \\
\hline \multirow[t]{3}{*}{$\begin{array}{l}\begin{array}{l}\text { Equity } \\
\text { (MEUR) }\end{array} \\
\end{array}$} & 9m 2019 & N/A & $45.100,00$ & $-176,80$ & $17.118,00$ & $22.544,00$ & & & & \\
\hline & $9 \mathrm{~m} 2020$ & N/A & $72.000,00$ & 430,10 & $10.866,00$ & $21.473,00$ & & & & \\
\hline & $\Delta \mathrm{EQ}(\%)$ & N/A & $59,65 \%$ & $343,27 \%$ & $-36,52 \%$ & $-4,75 \%$ & $90,41 \%$ & $169,26 \%$ & $-4,75 \%$ & $343,27 \%$ \\
\hline \multirow[t]{3}{*}{$\begin{array}{l}\text { Disclosure } \\
\text { (KB) }\end{array}$} & 9m 2019 & N/A & 870,00 & 898,00 & 831,00 & $1.130,00$ & & & & \\
\hline & $9 \mathrm{~m} 2020$ & 605,00 & 838,00 & 935,00 & 848,00 & 898,00 & & & & \\
\hline & $\Delta \mathrm{DC}(\%)$ & N/A & $-3,68 \%$ & $4,12 \%$ & $2,05 \%$ & $-20,53 \%$ & $-4,51 \%$ & $-8,21 \%$ & $-20,53 \%$ & $4,12 \%$ \\
\hline
\end{tabular}

Source: Authors' contribution.

Details of the main indicators we analyzed are explained below:

$\triangle \mathrm{R} \quad$-the difference in revenue between 9m2020 and 9m2019 divided by the $9 \mathrm{~m} 2019$

$\triangle \mathrm{EB} \quad$-the difference in EBITA AL between $9 \mathrm{~m} 2020$ and $9 \mathrm{~m} 2019$ divided by the $9 \mathrm{~m} 2019$

$\triangle \mathrm{MGPR} \quad$-the share of gross profit from total revenues

$\triangle N P \quad$-the difference in net profit between $9 \mathrm{~m} 2020$ and $9 \mathrm{~m} 2019$ divided by the $9 \mathrm{~m} 2019$

$\triangle \mathrm{MNPR}$-the share of gross profit from total revenues

$\triangle \mathrm{CF} \quad$-the difference in cash flow between 9m2020 and 9m2019 divided by the $9 \mathrm{~m} 2019$

$\triangle \mathrm{EQ} \quad$-the difference in equity between $9 \mathrm{~m} 2020$ and $9 \mathrm{~m} 2019$ divided by the $9 \mathrm{~m} 2019$

$\triangle \mathrm{DC} \quad$-the difference in disclosure between $9 \mathrm{~m} 2020$ and $9 \mathrm{~m} 2019$ divided by the $9 \mathrm{~m} 2019$ 
Observing the asymmetry of the figures, changes of the main indicators in the compared period, taking into account the real consequences (implementation and application costs, contractual changes, behavioural effects, regulatory effects, tax and dividend effects) of COVID-19 analyzed at the level of contracts with clients, we can say that there are also accounting consequences (recognition changes, measurement changes, presentation changes, disclosure changes) and cognitive consequences (internal and external users 'understanding of transactions, communication of effects to stakeholders) at the level of companies to be considered.

In the following we have briefly presented for each of the 4 companies how they have adapted to the new global pandemic context as well as some measures that have been taken accordingly with the mention that for Orange France they could not be identified.

\section{Altice INTL}

The COVID-19 pandemic had a minor impact on the Group's simplified interim consolidated financial statements, as of 30 September 2020, and for additional periods of three and nine months. The Group was hit by a decline in sales of handsets (low margin activity) leading to the closing of stores in many countries where the Group operates, a decrease in roaming revenue and a decrease in advertising agencies. Since the start of the recession, the effect has remained minimal, showing the resilience of the Company's telecommunications sector in the countries in which the Group operates.

\section{Telefonica}

Telefónica leveraged its network leadership during the crisis to further boost consumer loyalty, reflected in improved retention rates and NPS in our four core markets, and greater groupwide customer life.

During these difficult times, the group strong strategic emphasis has helped them to provide essential services and guarantee connectivity across their stable and safe network. This provided the basis for all their activities aimed at helping their partners and leading the post-COVID-19 economic recovery.

\section{TIM Italy}

The TIM Group registered non-recurring charges in the first nine months of 2020 for a total of EUR 181 million, of which EUR 89 million was due to the Covid-19 emergency in Italy. More precisely, in addition to the effects of the industrial customer service programs of TIM S.p.A., operational expenses were generated largely in relation to procurement and the credit protection provisions and charges arising from the weakening of the macroeconomic framework.

\section{Deutsche TELEKOM}

Deutsche Telekom created overall sales of EUR 17.5 billion in the first nine months of 2020 , up by 0.1 percent year-on-year and therefore practically on par with the previous year's amount. This rise was primarily attributed to the strong trend in their fixed network market on the basis of 5.5 percent growth in broadband sales and 2.0 percent in wholesale goods. Overall, the consequences of the coronavirus pandemic, such as temporary travel bans and the deteriorating economic climate, impacted sales throughout the year.

This had a negative effect on the sales of roaming, tourist, and terminal equipment and resulting in disruptions or postponements in the $\mathrm{B} 2 \mathrm{~B}$ telecommunications sector of existing orders. 
Variable sales elements, by comparison, grew favorably. In order to offset the overall decrease in sales, increase in fixed-network companies was sufficient.

\section{Orange France}

In the financial report of the first 9 months of 2020, Orange France did not separately identify the effect of the coronavirus pandemic on the main indicators.

As shown above, the most touted assembly line (AL revrec) of five steps simple model belonging to revenue recognition standard, in the face of uncertainties takes the shape of a prototype draft version or an overall designed concept, becoming actual a complex forward-backward steps iterative assembly winding stream (AWS revrec) model, which creates the need for a bigger repertoire.

As a consequence of our assessment, this new model for approaching the revenue recognition process could be formulated as follows:

where:

$$
\mathrm{AWS} \text { revrec }=\sum_{i=0}^{5} x i+\sum_{i=1}^{5} y i
$$

- $\mathrm{x}_{\mathrm{i}}$ represent the forward actions from the $i$ step ( $i=0$ denotes the enter to the first step);

- $\mathrm{y}_{\mathrm{i}}$ represent the backward actions from the $i$ step.

\section{Conclusion}

The way communications companies generate revenue is complex and varied. The sector comprises several sub-sectors, including cable or satellite (fixed line) television. Companies generate revenue through subscription fees or user charges that the user chooses to pay in exchange for the benefits stipulated in the offer. Offers in this area are diversified and include network access and facilities for the provision of voice, data, internet and television services, as well as some rental equipment (telephones/modems) or customer premises equipment and a variety of accessories. Consolidation, technological advances, and innovation have all influenced the communications industry's offerings. Multi-line plans (those in which customers attach more than one device to a service), installation of wireless devices, as well as bundled plans (with basic video services including voice and internet services) combined with home security services there can only be a few examples. Additionally, companies may offer services that go outside their traditional core offerings, such as cloud and machine-to-machine services.

Our analysis of the largest European companies during the COVID-19 crisis shows that for most companies the impact of the standard on accounting numbers was minimal. On the other hand, disclosures have generally increased.

The global context of continuous digitization has led to telecommunications companies not being deeply affected by the new coronavirus crisis. Although we have detailed the impact segments that should be reanalyzed and adapted in contracts, we can say that, overall, the services offered by these companies have experienced a significant increase, which also involves investments in communications infrastructure and continuous adaptability in recognizing customer needs.

With respect to information effects, there was limited evidence that companies would take the "opportunity" of the global pandemic to undertake an intensive review of their business and to adjust their business plan. 
Considering all the aspects presented, we wonder if at the time of developing the new standard was considered its application in crisis circumstances, in extreme situations in which companies are struggling to maintain their sustainability, in conditions of global economic uncertainty and if it can be on-goingly adapted, still presenting a flexibility in application.

The topic of our research highlights a new perspective related to the application of the new standard in conditions of global financial uncertainty, its adaptability, as well as the difficulties that the beneficiaries of financial reports may have following the interpretation of new data. We consider it is opportune to introduce elements that allow the flexibility of applying IFRS 15, as well as to perform a macro-scale analysis of the difficulties encountered by telecommunications companies and not only in order to review inconsistent possibilities.

We found that the content of the standard creates the conditions for increasing engagement and learning in cope of the uncertainties allowing a new iterative assembly winding stream model of revenue recognition for the authentic IFRS practitioners, users and setters.

We believe that our research will open new horizons in finding practical answers in the application of the new standard, that it will add value to existing literature, and that it will encourage telecommunications companies to make an in-depth analysis of the sustainability of the current framework for possible future improvements.

Main limitations of our research are represented by the investigation summarized only to the early 9 months period of the COVID-19 crisis implications, and by the small sample of corporate entities in telecommunications sector also, the comparability between various geographical areas in which telecommunications companies are operating, as the access to the specific accounting information was restricted. However, this theme may be extended and approached for future researches.

\section{References}

Aladwan, M. (2019). Fluctuations of Stock Price and Revenue after the Early Adoption of IFRS 15, Revenue from Contracts with Customers, Italian Journal of Pure and Applied Mathematics 41.

Ashbaugh, H., \& Pincus, M. (2001). Domestic accounting standards, international accounting standards, and the predictability of earnings, Journal of Accounting Research, 39(3).

Brozovic, M., \& Pavic, I. (2018). Analysis of the short- and long-term effects of the new revenue recognition standard on companies providing professional services. Proceedings of the 32nd International Business Information Management Association Conference, IBIMA, 2018. In Vision 2020: Sustainable Economic Development and Application of Innovation Management from Regional expansion to Global Growth.

Chayomchai, A. (2020). "The online technology acceptance model of generation-Z people in Thailand during COVID-19 crisis", Management \& Marketing. Challenges for the Knowledge Society, Vol. 15, No. Special Issue, 496-513, DOI: 10.2478/mmcks-2020-0029.

Cooper, S. (2010). Revenue recognition and your mobile phone. Retrived from http://www.ifrs.org. Dechow, P., Ge, W., \& Schrand, C. (2010). Understanding Earnings Quality: A Review of the Proxies, Their Determinants and Their Consequences, Journal of Accounting and Economics, 50(2-3).

Deloitte (2014). IFRS industry insights. Telecommunications sector.

Deloitte (2014). Previously, with the lack of detailed instructions in IFRSs, when determining the goods and services under a contract and then allocating the revenue to those goods and services, there was more room for judgment. As a consequence of the more detailed guid. 
Ferreira, A. F. (2020, 12 15). Retrieved from https://sigarra.up.pt/fep/pt/pub_geral.show_file?pi_ doc_id=252489.

Fonseca, L. and Azevedo A., (2020), "COVID- 19: outcomes for Global Supply Chains", Management \& Marketing. Challenges for the Knowledge Society, Vol. 15, No. Special Issue, 424-438, DOI: 10.2478/mmcks-2020-0025.

Jones, J., \& Pagach, D. (2013). The next step for revenue recognition, CPA Journal, 83 (10).

KPMG (2016). Revenue for telecoms, Issues in depth.

PICBE |

Leuz, C. (2003). IAS versus US GAAP: information asymmetry - based evidence from Germany's new market, Journal of Accounting Research, 445-472.

Leuz, C. (2003). IAS versus US GAAP: information asymmetry - based evidence from Germany's new market, Journal of Accounting Research, 41(3).

Leuz, C., \& Verrecchia, R. (2020). The economic consequences of increased disclosure, Journal of Accounting Research, 38.

Mattei, G., \& Paoloni, N. (2018). Understanding the Potential Impact of IFRS 15 on the Telecommunication Listed Companies, by the Disclosures' Study, International Journal of Business and Management, 14(1).

Napier, C., \& Stadler, C. (2020). The real effects of a new accounting standard:the case of IFRS 15 Revenue from Contracts with customers, Accounting and Business Research, 474-503.

Peters, J. (2018). Revenue Recognition: Top 10 Questions Investors Should Ask About the Adoption of The New Standard. Retrieved from https://www.cfainstitute.org/en/advocacy/ policy-positions/revenue-recognition-top-10-questions-investors-should-ask-about-theadoption-of-the-new-standard.

PWC (2017). In depth, A look at current financial reporting issues, Retrieved from PWC: www.pwc.com/structure.

Rutledge, R. W., Karim, K. E., \& Kim, T. (2016). The FASB's and IASB's New Revenue Recognition Standard: What Will Be the Effects on Earnings Quality, Deferred Taxes, Management Compensation, and on Industry-Specific Reporting? The Journal of Corporate Accounting \& Finance, 43-48.

Stubben, S. (2010). Discretionary revenues as a measure of earnings management, The Accounting Review, 85(2).

Tong, T. (2014). A Review of IFRS 15 Revenue from Contracts with Customers. Retrieved from http://www.masb.org.my/pdf.php?pdf=2014-09-15\%20Review\%20of\%20IFRS\%2015\% 20(TLT).pdf\&file_path=pdf, accessed in 12.02.2020.

Tutino, M., Regoliosi, C., Mattei, G., Paoloni, N., \& Pompili, M. (n.d.). Does the IFRS 15 impact earnings management? Initial evidence from Italian listed companies, African Journal of Business Management 13(7).

Usurelu, V., \& Dutescu, A. (2020). Challenges and controversies related to IFRS 15 implementation, Springer Proceedings-Business Revolution in a Digital Era.

https://www.telekom.com/en/investor-relations/publications/financial-results.

https://www.telefonica.com/en/web/shareholders-investors/financial_reports/annual-report.

https://www.orange.com/en/consolidated-results.

https://www.gruppotim.it/en/investors/reports-presentations/financial-reports.html.

http://altice.net/investor-relations.

https://assets.kpmg/content/dam/kpmg/xx/pdf/2020/04/telecommunications-financial-reportingimplications-of-covid-19.pdf. 
https://www.pwc.com/gx/en/audit-services/ifrs/publications/ifrs-15/in-depth-ifrs-15-industrysupplement-communications.pdf.

https://home.kpmg/xx/en/home/insights/2014/06/revenue-leaflet-telecommunication.html.

https://assets.kpmg/content/dam/kpmg/xx/pdf/2016/09/revenue-for-telecoms-issues-in-depth2016.pdf.

International Accounting Standards Board [IASB]. (2014). IFRS 15 Revenue from Contracts with Customers.

International Accounting Standards Board [IASB]. (1993). IAS 18 Revenue Recognition. 